\title{
EFSUMB Congress in Athens
}

The EFSUMB congress this year will be held in Athens, Greece. The main objective of the congress is to inform, educate and update physicians of all specialties on all conventional, current and emerging fields of Ultrasound.

The scientific program consists of categorical courses which aim to educate and inform attendees in all anatomical areas where ultrasound can be applied. There are refresher courses which cover all areas of expertise and Practical Courses with hands-on availability for all participants. The program is enriched with plenary sessions, satellite symposiums and key-note speakers. During the congress EFSUMB and ENSCH will present new ultrasound guidelines.

The local organizing committee will also present innovative ultrasound guided procedures of diagnostic and therapeutic value!
The congress will be held in Athens Hilton, one of the best located congress hotels in Athens. Attractive rates are offered for all kinds of hotel categories. Finally an extensive program of sightseeing possibilities will be offered before, throughout and after the congress.

Deadline for abstracts approaching soon, register now!

Looking forward to seeing you in Athens!

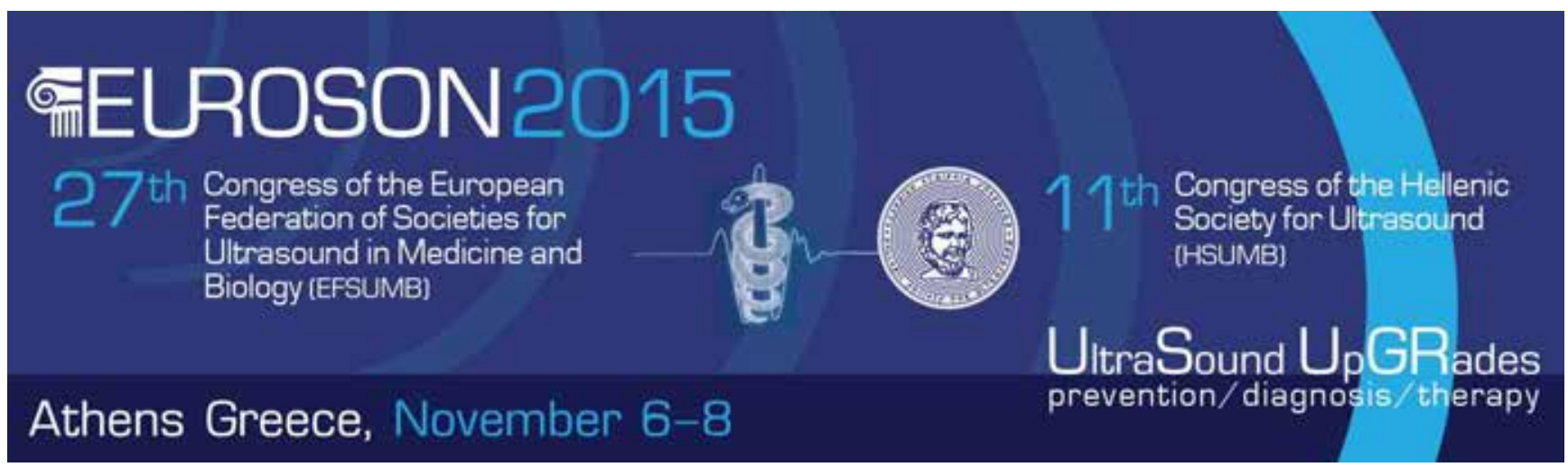

